Original Article

\title{
A Study to Assess the Knowledge Regarding PCOS (Polycystic Ovarian Syndrome) among Nursing Students at NUINS.
}

\section{Sunanda B. ${ }^{1}$, Sabitha Nayak ${ }^{2}$}

${ }^{1}$ Lecturer, ${ }^{2}$ Vice Principal \& HOD, Dept. of OBG, Nursing, Nitte Usha Institute of Nursing Sciences, Paneer, M angalore.

*Corresponding Author : Sunanda B., Lecturer, Dept. of OBG Nursing, Nitte Usha Institute of Nursing Sciences, Nitte University, Paneer, Mangalore-575018. Mobile:9482098457 E-mail:sunanda@ nitte.edu.in.

Received

: 24-12-2015

Review Completed : 26-07-2016

Accepted

:17-08-2016

Keywords : Knowledge, PCOS, Nursing Students

\begin{tabular}{|c|}
\hline Access this article online \\
\hline Quick Response Code \\
\hline
\end{tabular}

\section{Abstract:}

Polycystic ovarian syndrome is an endocrine disorder which affects the adolescent girls. It has been found through studies that it affects around $5 \%$ to $10 \%$ of women in their reproductive years. The study was conducted to assess the knowledge on the polycystic ovarian syndrome among the student nurses. The data was collected from the nursing students by using structured questionnaire. The data collected from 150 samples in Nitte Usha Institute of Nursing Sciences. Descriptive survey research approach was adopted and data was analyzed by using descriptive and inferential statistics. Distribution of the samples on demographic characteristics revealed that $85 \%$ of the samples were in the age group of $21-25 y e a r s, 75 \%$ of the samples were Christians, $82 \%$ of the samples were consuming mixed diet, and $92 \%$ samples had regular menstrual cycle. $76 \%$ of the samples were with average knowledge and $10.7 \%$ with good knowledge regarding polycystic ovarian syndrome. Hence the study concluded that Source of information, consumption of junk food, dietary patterns of the students were associated with their level of knowledge on PCOS at $5 \%$ level of significance.

\section{Introduction}

Adolescent period is a unique period where there is a change from childhood to adulthood, a time of physiological, psychological, social and emotional adaptation. During this period individual attains physical and sexual maturity, whereas emotional maturity will be imbalanced. The changes in adolescent period have important implications to understand the health risks associated with this syndrome. ${ }^{1}$ during this period, the body changes and there will be development of secondary sex characteristics. Any difference of secondary sex characteristics can inversely affect the physical and emotional adaptation of the adolescent.

Polycystic ovarian syndrome is a condition in which woman has an imbalance of female sex hormones. This may lead to changes in the menstrual cycle, cyst in the ovary, failure to conceive and other health problems. It is a common health problem among teenagers and young women. It affects $5 \%$ to $10 \%$ of women in their reproductive years. These problems causes infertility. Although there is no cure for
PCOS, there are several ways to treat and manage the condition. If a girl is overweight, Weight loss can be very effective in lessening many of the health conditions associated with PCOS. Sometimes weight loss alone can restore hormone level to normal, causes many of the symptoms to disappear or become less severe. Healthy food habits and exercise helps to combat the weight gain. Research has suggested that PCOS may be related to increased insulin production. PCOS seems to run in families, too, so if someone in the family has it, they might be more likely to develop it. India has witnessed about 30\% rise in polycystic ovarian syndrome (PCOS) cases in the last couple of years. Lack of knowledge and lifestyle changes are considered to be the major factor leading to this phenomenon. There is a need to increase awareness among women so as to avoid major cases of fertility problems in the future. A Nurse holds a critical role in health care that goes beyond the day to day duties. Nurses are in a position to provide comprehensive care to adolescent afflicted with the syndrome. Essential elements 
of nursing practice should be included in the nursing education. So upgrading the knowledge regarding PCOS to nursing students will enhance the adolescent girls to modify their lifestyle and reduce the risk.

\section{Materials and methods}

Descriptive survey approach and descriptive design was adopted in this study. The study was conducted on 150 $2^{\text {nd }}$ year and III year B.Sc. Nursing students of Nitte Usha Institute of Nursing Sciences by using simple random sampling technique.The data was collected by using structured knowledge questionnaire on PCOS which consists of 20 items. The investigator obtained permission from the authorities of the college, prior to the data collectionand assured confidentiality to the subject to get their cooperation and explained the purpose of the study. The results were analyzed through descriptive and inferential statistics.

\section{Results}

Most of the students (85\%) were in the age group of 2125years. Most of the students were Christians (75.3\%). Among the students, $82.7 \%$ were consuming mixed diet, $4 \%$ of the students were exclusively vegetarians. $92 \%$ of the students had regular menstrual cycle.

Level of knowledge of the students was assessedthrough frequency and percentage which depicts that most of the students (114) had averageKnowledge (76\%).

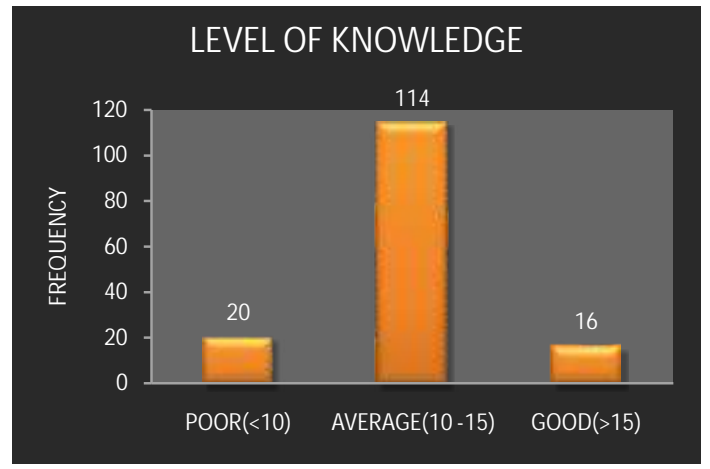

\begin{tabular}{|c|c|c|c|c|c|c|}
\hline \multicolumn{2}{|l|}{ Characteristics } & Poor & Average & Good & Test statistic & $P$ value \\
\hline \multirow[t]{2}{*}{ Age } & $18-20$ & 17 & 98 & 13 & \multirow{2}{*}{ 0.533(Fisher's exact) } & \multirow{2}{*}{0.854} \\
\hline & $21-25$ & 3 & 16 & 3 & & \\
\hline \multirow[t]{4}{*}{ Religion } & Hindu & 5 & 16 & 2 & \multirow{4}{*}{ 2.972(Fisher's exact) } & \multirow{4}{*}{0.812} \\
\hline & M uslim & 0 & 2 & 0 & & \\
\hline & Christian & 14 & 87 & 12 & & \\
\hline & Others & 1 & 9 & 2 & & \\
\hline \multirow[t]{2}{*}{ Course Of Study } & $2^{\text {nd }}$ B.Sc. $(\mathrm{N})$ & 12 & 53 & 8 & \multirow{2}{*}{ 1.256(Chi-square) } & \multirow{2}{*}{0.549} \\
\hline & $3^{\mathrm{RD}}$ B.Sc. $(\mathrm{N})$ & 8 & 61 & 8 & & \\
\hline \multirow[t]{3}{*}{ Dietary Pattern } & Veg. & 3 & 1 & 2 & \multirow{3}{*}{ 17.007(Fisher's exact) } & \multirow{3}{*}{$0.001 *$} \\
\hline & Non-veg. & 6 & 13 & 1 & & \\
\hline & Mixed & 11 & 100 & 13 & & \\
\hline \multirow{3}{*}{$\begin{array}{l}\text { How Often Do } \\
\text { You Consume } \\
\text { Non-Veg. }\end{array}$} & Weekly once & 6 & 15 & 0 & \multirow{3}{*}{ 10.193(Fisher's exact) } & \multirow{3}{*}{$0.029 *$} \\
\hline & Weekly twice & 9 & 63 & 6 & & \\
\hline & >twice in a week & 5 & 36 & 10 & & \\
\hline \multirow{2}{*}{$\begin{array}{l}\text { Do You Like } \\
\text { Junk Food }\end{array}$} & Yes & 11 & 57 & 13 & \multirow{2}{*}{ 5.525( Chi-square) } & \multirow{2}{*}{$0.063^{*}$} \\
\hline & No & 9 & 57 & 3 & & \\
\hline \multirow{3}{*}{$\begin{array}{l}\text { Amount of Water } \\
\text { Intake Per Day }\end{array}$} & $500-1000 \mathrm{ml}$ & 13 & 69 & 13 & \multirow{3}{*}{ 4.485(Fisher's exact) } & \multirow{3}{*}{0.289} \\
\hline & $1000-2000 \mathrm{ml}$ & 5 & 41 & 3 & & \\
\hline & $>2000 \mathrm{ml}$ & 2 & 4 & 0 & & \\
\hline \multirow{2}{*}{$\begin{array}{l}\text { Regularity Of } \\
\text { Menstrual Cycle }\end{array}$} & Regular & 0 & 10 & 2 & \multirow{2}{*}{ 2.148(Fisher's exact) } & \multirow{2}{*}{0.329} \\
\hline & Irregular & 20 & 104 & 14 & & \\
\hline \multirow{2}{*}{$\begin{array}{l}\text { Menstruation } \\
\text { disorder }\end{array}$} & Yes & 20 & 109 & 15 & \multirow{2}{*}{ 0.962(Fisher's exact) } & \multirow{2}{*}{0.608} \\
\hline & No & 0 & 5 & 1 & & \\
\hline \multirow{6}{*}{$\begin{array}{l}\text { Source of } \\
\text { information }\end{array}$} & Health personnel & 3 & 25 & 4 & \multirow{6}{*}{ 15.968(Fisher's exact) } & \multirow{6}{*}{$0.058^{*}$} \\
\hline & Friends & 2 & 12 & 0 & & \\
\hline & Parents & 5 & 34 & 7 & & \\
\hline & Teachers & 4 & 36 & 2 & & \\
\hline & Mass medias & 5 & 5 & 3 & & \\
\hline & No information & 1 & 2 & 0 & & \\
\hline
\end{tabular}


The above table shows that there is an association between knowledge on PCOS and demographic variables such as dietary pattern, consumption of non-vegetarian, consumption of junk food and source of information.

\section{Discussion}

The study was conducted on 150B.Sc. nursing students to assess the knowledge regarding PCOS. Students above 18 years of age were included in this study. Most of the students were in the age group of $21-25$ years $(85 \%)$. Analysis was done by frequency percentage. The level of knowledge was categorized into poor (13.3\%), average (76.0\%) and good (10.7\%).The finding of the study shows

\section{References}

1. Mskalpana S.P,A study to evaluate the effectiveness of structured teaching programme regarding polycystic ovaries among the student of selected pre-university colleges in Banglore.2011 June a. Available from URL: http://www.rguhs.ac.in/cdc/onlinecdc.

2. AfsanehKhademi MD, Ashraf Alleyassini MD and MehrnooshAmini MD. The effect of exercise in PCOS women who exercise regularly.2009 Nov.

a. Available from URL: www.ncbi.nlm.nih.gov/pmc/articlespmc 3289164/ \#! Po=s10,0000

3. Richard Scott lucidi MD, FACOGI chief editor, 2014 sept. Polycystic ovarian syndrome overview.

a. Available from URL: http://emedicine.Medscape.com/article/ 256806-overview

4. Hadayat.A.AM ASHA, Manar.F.Heeba, Department of Obstetrics and Gyanaecology nursing, Egypt faculty of Nursing, Implementation and evaluation of effectiveness of educating programme for upgrading Nurses knowledge regarding PCOS.

a. Available from URL: http://iosrjournals.org/isor.jnhs/A-03140108.

5. Centre for young women health. Polycystic ovary syndrome (PCOS).A guide for teens.

a. Available from URL:http://www.youngmenshealth.org/index. html

6. Http:// www.healthshare.com.au/questions/2177-can-polycysticovarian-syndrome-pcos-be-cured

7. Health wise webmed Available from URL:http://women.webmed.com /tc/ polycystic-ovary-syndrome-pcos-topic-overview,may 2010.

8. Suja Nair Shirodkar, India witnesses alarming incidence of pcos.

9. Available from URL:http://ay.urbhishak.wordpress.com/2010/09 123/\%e2\%99\%a3-india-witnesses-alarming-rise-in-incidence-ofpcos-dr-rajeev-punjabi/

10. Synder B.S. Pcos in adolescent patients: recommendations for that majority (114) of students had average knowledge.

\section{Conclusion}

Due to the varied nature of PCOS and the large range of possible signs and symptoms, health personnel need a thorough knowledge of the disorder and its management. Nurses should be aware of the various organizations which render support. Counselingfor adolescents should be includedin the curriculum which will provide an awareness towards the disorder and lifestyle modification. In this study the $2^{\text {nd }}$ and $3^{\text {rd }}$ year BSc. (N) students hadaverage knowledge on polycystic Ovarian Syndrome.

practice. Pediatric Nursing 2005 sept-oct; 31(5):416.

11. The Hindu, Alarming rise in hormone disorder among young girls.Onlineedition, Apr25, 2005.

a. Available from URL:http://www.hinduonnet.com/2005/04/ stories/2005042507400500.html

12. Bhattacharya S M, Metabolic syndrome in females with polycystic ovary syndrome and international diabetes federation criteria.2008 Feb; 34(1):62-6.

a. Available from URL:http://www.ncbi.nlm.nihgov/pubmed./ 18226131

13. Nidhi R, Nagaratna R, Amrithanshu R. Prevalence of polycystic ovarian syndrome in Indian adolescents. 2011 Aug; 220-4

14. Salehpour A, Esmaeitnia H, Enlezari A. Evaluation of prevalence of PCOS among adolescent girls in Tehran. Tehran during 2005-2006. International Journal of Fertility and Sterility 2010 Oct-Dec;4(3):122-7.

15. Yildiz BO, Azziz R. Impact of obesity on risk for PCOS. The Journal of Clinical Endocrinology and M etabolism 2008Jan;93(1):162-8.

16. Majundar A, Singh TA. Comparison of clinical features and health manifestation in lean v/s obese Indian women with PCOS. Journal of Human Reproductive Sciences 2009 Jan;2(1):12-7.

17. Hollinrake E, Dokras A, Voorhis B. Increased risk of depressive disorder in women with PCOS. Fertility and Sterility 2007 Jan;87(6):1369-76.

18. Shanmugasundaram S. Effectiveness of structured teaching programme on PCOS awareness among adolescent girls in a selected rural area. Chennai. India. Abster Academy Health Meet. [Online]. Available from: URL:http/www.google.com

19. Dhital AD, Badhu B. Effectiveness of structured teaching programme in improving knowledge and attitude of school going adolescents on reproductive health. Kathmandu University Medical Journal 2005:3(12):380-3. 